\title{
Reseñas
}

https://doi.org/10.29393/RH27-22AUMO10022

\section{Mario Garcés, El movimiento obrero y el Frente Popular (1936-1939), Santiago de Chile, LOM ediciones, 2018, 156 páginas. ISBN: 978-956-00-1062-9.}

Andrea Uribe, Editora en Historiográfica. ORCID: https://orcid.org/0000-0001-7877-2818

Si esta reseña llevase un título sería "Prehistoria de un historiador", puesto que Mario Garcés - doctor en Historia, profesor de la Universidad de Santiago y director de ECO, Educación y Comunicaciones - nos ofrece, con esta publicación, la oportunidad única de conocer la investigación con la que cerró su licenciatura. Ocurre que, por vaivenes académicos o personales, más la realidad del mundo editorial, lo primero que solemos leer de un historiador o historiadora es su tesis de doctorado y, por entonces, bastante agua ha corrido bajo el puente de su oficio. Así que estamos frente a un texto escrito en 1985, cuando Fondecyt no existía. Todo un riesgo para el ego que solo podemos felicitar.

Los años pasaron, los libros también. Tomando su sitio. El movimiento de pobladores de Santiago (1957-1970), El golpe en La Legua. Los caminos de la historia y la memoria (en coautoría con Sebastián Leiva), el reciente Pan, trabajo, justicia y libertad. Las luchas de los pobladores en Dictadura (1973-1990), son algunas de las obras que Garcés ha compartido con sus lectores y lectoras, cuyos títulos demuestran que su interés intelectual tomó su sitio en el alba de su carrera. ¿Resultado de un compromiso político, emocional, ambos o ninguno?

Cualquiera sea la respuesta, cuando El movimiento obrero y el Frente Popular (1936-1939) salió de imprenta encontró a su autor convertido en un historiador más que merecedor del Premio Nacional de Historia. Hablamos de un libro sencillo, resultado de una investigación temprana, anhelante y necesaria pues "como toda historiografía que se piense con sentido social, [...] entrega valiosos elementos para leer este momento de cambio sistémico al que algunos aspiran y otros rechazan y resisten"1 (la cita parece particularmente acertada tras octubre del año pasado, ahora que todo se lee distinto). Dispongámonos, entonces, a mirarlo, a leerlo y a pensarlo.

Tres capítulos lo conforman. En el primero, llamado "Los condicionamientos económicos, sociales y políticos de los años treinta", nos situamos: los efectos de la crisis económica del 29 se hacen sentir, la dependencia extractiva es manifiesta, existe pobreza y hacinamiento pese a las leyes sociales dictadas como consecuencia de la Cuestión Social y el sistema político se

\footnotetext{
1 Valdivia O. de Z., Verónica. 2018. “Prólogo”. En Garcés D., Mario. El movimiento obrero y el Frente Popular (19361939), Santiago de Chile, LOM ediciones, p. 11.
} 
quiebra (1931-1932) y se restaura (1932-1938). Nace por entonces, como hijo de la movilización y el desconcierto, el Frente Popular, alianza social y política establecida entre los sectores medios y los sectores populares.

Por cierto, no fue fácil. Del trayecto seguido por cada partido para integrar la coalición podemos enterarnos en las páginas que conforman este primer capítulo, donde destaca el caso del Partido Comunista. Tras el triunfo nazi en Alemania, el Séptimo Congreso de la Tercera Internacional reestructuró su línea política, transitando desde una férrea oposición a la socialdemocracia a declarar que lo más importante será la defensa del sistema democrático, lo que en Chile tomó dos caminos: la constatación de que la revolución chilena tendría que recorrer etapas y el establecimiento de alianzas como estrategia de avance (son los frentes populares antifascistas). Solo entonces el comunismo chileno se hizo parte de esta empresa. Es 1935. Al año siguiente el movimiento obrero se unifica en la primera central de trabajadores. Conversaciones, discusiones, acuerdos, alianzas.

Claro está que la liga comenzó su gestación antes. La legislación laboral de 1924 estableció un sindicalismo legal que adjudicó al Estado derechos sobre la organización obrera, que el Código del Trabajo consagró en 1931. Tras una década de leyes sociales tenemos un movimiento sindical con tres representantes: la Federación Obrera de Chile (FOCH), de orientación comunista; la Confederación General del Trabajo (CGT), de orientación anarquista; y la Confederación Nacional de Sindicatos (CNS), influenciada por el Partido Socialista. Orientaciones, diferencias, desacuerdos.

Enero de 1935 es testigo de la primera huelga general ferroviaria nacional, muy bien investigada y elegantemente narrada en el capítulo 2, llamado "De las huelgas ferroviarias a la conformación de una central única de los trabajadores (1935-1936)". Huelgas, en plural, puesto que en febrero del año siguiente se desarrolla la segunda huelga general ferroviaria nacional, esta vez acompañada con la paralización de otros gremios. Escritura amable y fácil lectura que nos llevan a la estructuración de nuestra primera central obrera: la Confederación de Trabajadores de Chile (CTCH). Pero este nacimiento no fue el único registrado durante 1936. El 9 de marzo se oficializa el Frente Popular con las firmas de los partidos Socialista, Radical, Radical Socialista, Democrático, Comunista e Izquierda Comunista. Es la unidad de la izquierda.

En el tercer capítulo nos sumergimos en la historia de la $\mathrm{CTCH}$, desde su Congreso Constituyente acaecido entre el 25 y el 27 de diciembre de 1936 hasta su quiebre en 1946, pasando por su ingreso al Frente Popular en 1937 y posterior apoyo a la candidatura presidencial de Pedro Aguirre Cerda. Dos orientaciones - comunista y socialista - conviven hasta que, ante la imposibilidad de consensuar, producen la fractura. Sin embargo, antes de ella hubo una década de unión en la que se aceptó, en el seno de la central, la existencia de sindicatos legales y sindicatos libres, pues se intentó caminar hacia un movimiento sindical institucionalizado reconociendo la lucha de clases. Unidad plasmada en un programa que 
incluyó la defensa de la Constitución del 25 y la ampliación de la democracia, junto a una compartida acción política, social, económica y cultural. Unidad que se trizó, precisamente, frente a la existencia de un sindicalismo legal y otro libre, ante la pregunta sobre cómo concebir la unidad y ante el compromiso político establecido con el Frente Popular.

Por tres años transcurre este libro. Tres años, diríamos, convulsionados. Tras el arranque del siglo XX -emergencia de sectores medios y proletarios, Cuestión Social, Constitución del 25, Código del Trabajo, Gran Depresión de los años 29 y 30- y desplegadas dos exitosas huelgas generales, el movimiento sindical busca institucionalizarse para, de esa forma, incidir con sus justas demandas en el aparato estatal. Algo similar desarrolló, tras la recuperación democrática, el pujante movimiento feminista chileno de los ochenta con la creación del Sernam. ¿Será, la incidencia, una estrategia poderosa?

La realidad material que este libro constituye lleva la firma de LOM ediciones, cuya colección Historia destaca por su inmensa calidad y consistencia. Algunas erratas nos hablan, eso sí, de una corrección de estilo no acabada, algo lamentable pues entorpece la comprensión tanto como el diseño de títulos y subtítulos, que se mimetizan con el cuerpo del texto. Aspectos fácilmente mejorables y que en ningún caso invitan a abandonar la lectura.

La práctica investigativa de Mario Garcés se ha centrado en los sujetos populares - obreros, pobladores, movimientos sociales - , variando en el espacio y en el tiempo en que se aboca; labor que ha acompañado de un trabajo político con asambleas territoriales y desarrollando proyectos de educación popular e historia local. Es, me parece, un historiador con un profundo compromiso social. Así lo encontramos en el presente. En el pasado, hubo un estudiante de Historia que el año 85, para obtener su licenciatura, quiso indagar en el movimiento obrero y su relación con el Frente Popular. Revisó archivos (los anexos de este estudio son riquísimos) mientras afuera de la Biblioteca Nacional llovían lacrimógenas, para encontrar, por ejemplo, que El Mercurio bajó el alcance de las huelgas generales del 35 y el 36, tal como lo hacía en su presente dictatorial y en este presente continúa haciéndolo. Escribió y, hoy, esa investigación tiene forma de libro. 